\title{
To investigate the diagnosis and management of common functional gastrointestinal disorders (FGIDs) and their effect on the quality of life in infants 0-6 months
}

\author{
B. Coffey ${ }^{1}$, J.L. O’Neill ${ }^{2}$, E. Shannon ${ }^{2}$, N. Dennehy ${ }^{2}$ and A. Regan ${ }^{2}$ \\ ${ }^{1}$ UCD Institute of Agriculture and Food Science, University College Dublin, Belfield, Dublin 4, Republic of Ireland and \\ ${ }^{2}$ Danone Nutricia Early Life Nutrition, Block 1 Deansgrange Business Park, Deansgrange, Co. Dublin, Republic of \\ Ireland
}

Infants complete a significant portion of their development after they are born, including that of their digestive system ${ }^{(1)}$. As a result, many infants experience a number of digestive and feeding difficulties in early life. The term functional gastrointestinal disorders (FGIDs) refers to a diverse group of recurrent symptoms and feeding problems ${ }^{(2)}$.

The aim of this study is to investigate methods of diagnosis ${ }^{(3)}$ and recommendations for first line treatment in the management of common FGIDs in infants 0-6months and then to further assess the attitudes of healthcare professionals towards the effect that FGIDs have on the quality of the infant's and the wider family's life.

Healthcare professionals (general practitioners (26), public health nurses (29), practice nurses (13) and other (8)) completed either a hard copy or online questionnaire including a total of 17 questions. A total of 76 questionnaires were completed and further analysed.

Out of the three most prevalent FGIDs; colic, constipation and reflux/regurgitation ${ }^{(4)}$, colic was viewed as the most prevalent condition with $45 \%$ of healthcare professionals (HCPs) deeming it as the most common, followed by reflux/regurgitation at $38 \%$ and constipation at $17 \%$. However, $88 \%$ of participants were not aware of the ROME ${ }^{(3)}$ criteria for the diagnosis of FGIDs.

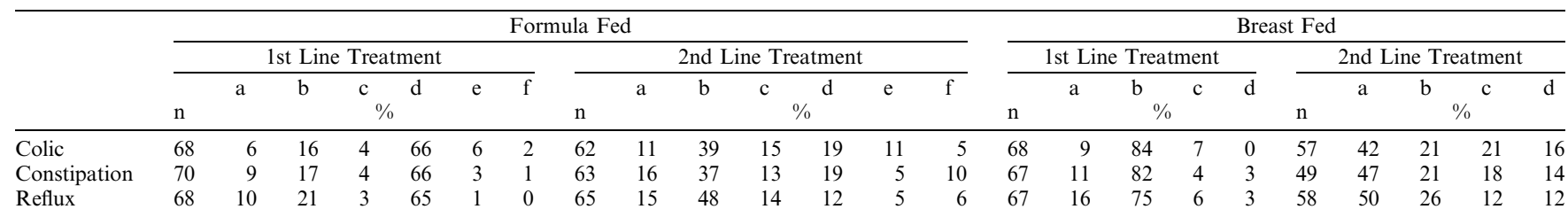

Formula Fed: $\mathrm{a}=$ Medicinal treatment, $\mathrm{b}=$ Formula change, $\mathrm{c}=$ Both medicine and formula change, $\mathrm{d}=$ Parental reassurance/guidance, $\mathrm{e}=$ No action, $\mathrm{f}=$ Other.

Breast Fed: $\mathrm{a}=$ Medicinal treatment, $\mathrm{b}=$ Parental reassurance/guidance, $\mathrm{c}=$ No action, $\mathrm{d}=$ Other

The most prevalent first line treatment for colic, constipation and reflux in both formula fed (FF) and breast fed (BF) infants was parental reassurance. The most common secondary treatment for FF infants was a change in formula while for BF infants it was medicinal treatment.

When asked whether colic, constipation and reflux/regurgitation impacted quality of life for the infant, main care giver and entire family home, colic was deemed to give the most negative impact with $82 \%, 92 \%$ and $82 \%$ respectively believing it affects quality of life. For constipation, $82 \%, 70 \%$ and $38 \%$ of HCPs deemed it as having a negative impact on the quality of life for the infant, main care giver and entire family home respectively, while reflux/regurgitation was viewed to impact quality of life negatively by $78 \%, 43 \%$ and $52 \%$ respectively.

This study suggests that in a sample of Irish HCPs a strong belief in the use of parental reassurance for first line treatment of FGIDs, poor knowledge of FGID diagnosis criteria and a good awareness of the effect they have on quality of life.

This study was funded by Danone Nutricia Early Life Nutrition, Deansgrange, Dublin, Republic of Ireland.

1. Food Safety Authority of Ireland (FSAI). (2012) Best Practice for Infant Feeding in Ireland. From Pre-conception through the first year of an infant's life. A guide for healthcare professionals based on scientific recommendations for a National Infant Feeding Policy. FSAI.

2. Hyman PE et al., (2006) Childhood functional gastrointestinal disorders: Neonate/Toddler. Gastroenterol 130, $1519-1526$.

3. Benninga MA. et al., (2016) Childhood Functional Gastrointestinal Disorders: Neonate/Toddler. Gastroenterology 150, $1443-1455$.

4. Vandenplas Y et al., (2013) Prevalence and health outcomes of functional gastrointestinal symptoms in infants from birth to 12 months of age. J Pediatrics 131(5), e1684-e1695. 